\title{
Temperature dependence of stress in CVD diamond films studied by Raman spectroscopy
}

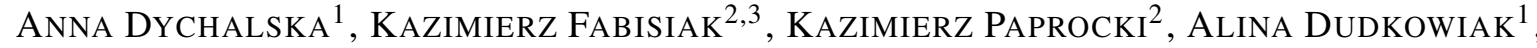 \\ MiROSŁAW SZYBOWICZ ${ }^{1 *}$ \\ ${ }^{1}$ Faculty of Technical Physics, Poznan University of Technology, Piotrowo 3, 60-965 Poznan, Poland \\ ${ }^{2}$ Institute of Physics, Kazimierz Wielki University, Powstańców Wielkopolskich 2, 85-090 Bydgoszcz, Poland \\ ${ }^{3}$ Medical Physics Department, Oncology Center, I. Romanowskiej 2, 85-796 Bydgoszcz, Poland
}

Evolution of residual stress and its components with increasing temperature in chemical vapor deposited (CVD) diamond films has a crucial impact on their high temperature applications. In this work we investigated temperature dependence of stress in CVD diamond film deposited on $\mathrm{Si}(100)$ substrate in the temperature range of $30{ }^{\circ} \mathrm{C}$ to $480{ }^{\circ} \mathrm{C}$ by $\mathrm{Raman}$ mapping measurement. Raman shift of the characteristic diamond band peaked at $1332 \mathrm{~cm}^{-1}$ was studied to evaluate the residual stress distribution at the diamond surface. A new approach was applied to calculate thermal stress evolution with increasing temperature by using two commonly known equations. Comparison of the results obtained from the two methods was presented. The intrinsic stress component was calculated from the difference between average values of residual and thermal stress and then its temperature dependence was discussed.

Keywords: Raman spectroscopy; stress; diamond structure; CVD diamond films

(C) Wroclaw University of Technology.

\section{Introduction}

Diamond structures are promising materials for production of high-power microelectronic elements thanks to fine thermal and electrical properties, like high thermal conductivity and low thermal expansion coefficient or high breakdown voltage and p-type conductivity in H-terminated surface of CVD diamond films [1-3]. Moreover, the implementation of thin diamond films in industry as chemical electrodes, high-power transistors or biosensors transducers has already started $[2,4]$.

The general problem with high temperature application of CVD diamond films is the presence and evolution of stress in the layers due to thermal mismatch between the film and the substrate CTE (coefficient of thermal expansion). Another sources of stress are also defects and impurities incorporated in the layer [5]. The component called the intrinsic stress is a measure of quality of diamond and

*E-mail: miroslaw.szybowicz@put.poznan.pl should remain roughly constant during re-heating process. Residual stress in CVD diamond film, which is a sum of two mentioned above components, can lead to changes in mechanical or electrical properties or even to failure of the deposited film. Therefore, it is important to study the level and character of stress in the film, especially at its potential operating temperature. There is a number of methods for stress measurement in CVD diamond films [6]. The Raman spectroscopy has been frequently used in stress measurement because it is fast and non-invasive. Using this spectroscopic method, stress might be evaluated from the diamond band shift at $1332 \mathrm{~cm}^{-1}$, which is an unambiguous evidence of the presence of diamond phase in a deposited carbon layer [7-9]. The Raman spectrum of non-stressed, pure diamond monocrystal has only one sharp line which is a result of the facecentred cubic symmetry. At $0 \mathrm{~K}$ a triply degenerate first order phonon arises at $1332.5 \mathrm{~cm}^{-1}$, and if stress appears, the band is shifted to the lower or higher wavenumbers, which corresponds to tensile or comprehensive stress, respectively [5]. 
Many of recent publications [5, 10-12] have concerned the measurement and calculation of stress in CVD diamond films by combining one of residual stress measurement techniques, like substrate curvature, X-ray diffraction or Raman spectroscopy with bi-metal plate-bending theory, however, most of them have neglected the temperature dependence of thermal expansion coefficients (CTE) [6].

The CVD diamond films are usually deposited on the substrates having CTE much different from that of diamond and additionally their temperature dependencies are also different. In diamond application for high temperature coatings or devices, the stress evolution with temperature has to be taken under consideration.

According to our best knowledge no report has been published on the post deposited evolution of thermal stress in CVD diamond films with temperature, therefore, in this paper, we have provided accurate calculation of thermal stress by two models. We also show how each component of residual stress changes with increasing temperature by proposing a new approach to their calculation.

\section{Experimental}

Two samples of CVD thin diamond films, DPK36 and DPK37, were deposited on silicon substrates, scratched earlier with diamond paste to improve nucleation, and then washed in ultrasonic bath with methanol, chloroform and deionized water. Silicon wafers used as substrates had a thickness of $0.4 \mathrm{~mm}$ and (100) orientation. The two samples were deposited by hot filament (HF) CVD technique. During HF CVD process, the temperature of substrates was $1290{ }^{\circ} \mathrm{C}$ for both samples, total pressure in the reactor chamber was $6 \mathrm{kPa}$ and $10 \mathrm{kPa}$, respectively, but the percentage contribution of methane in the working gas was the same, $2.98 \%$. These deposition parameters and different nucleation times (1410 min for DPK36 sample, $600 \mathrm{~min}$ for DPK37 sample) gave samples DPK36 and DPK37 of 4.46 and $0.34 \mu \mathrm{m}$ thickness, respectively.

Raman measurements were performed using a Renishaw in Via Raman spectrometer. Confocal mode allowed recording spectra with $2 \mu \mathrm{m}$ confocal resolution. As an excitation wavelength we used tuneable Ar ion laser working at $488 \mathrm{~nm}$ with power of $1 \mathrm{~mW}$. The spectra were recorded in static mode with a centre at $1300 \mathrm{~cm}^{-1}$ in the spectral range from 800 to $1800 \mathrm{~cm}^{-1}$. We used the technique of spectra accumulation (10 accumulations) to obtain good quality Raman spectra (high signal to noise ratio) and enhance the intensity of the Raman bands of the studied thin diamond layers. In order to study temperature shift of the diamond band, during the measurements the samples were placed in a temperature stage Linkam THMS 600, which allowed gradual increasing of temperature. For samples DPK36 and DPK37 Raman mapping measurements were performed at 30, 80, 130, 180, $230,300,380,480{ }^{\circ} \mathrm{C}$ for an area of $20 \times 20 \mu^{2}$ with a step of $2 \mu \mathrm{m}$.

Renishaw WiRE 3.4 software, besides data collection, was used for deconvolution of the obtained spectra by the curve fitting method using a mix of Lorentz and Gauss functions.

\section{Results and discussion}

Examples of Raman spectra of CVD diamond films DPK36 and DPK37 recorded at 8 different temperatures are shown in Fig. 1a and Fig. 1b, respectively. The diamond band position is found to be shifted to lower wavenumbers with increasing temperature. Moreover, no clear splitting of the diamond band is observed, which indicates the lack of anisotropic stress. The anisotropic stress, if sufficiently high, can remove partially or completely the lift of the threefold degeneracy of optical phonon in the Brillouine zone centre $[5,11]$. In this case, residual stress is hydrostatic and it can be calculated from equation $1[9,13]$ :

$$
\sigma_{R}=-0.567\left(v_{m}-v_{0}\right)
$$

where $v_{\mathrm{m}}$ is the observed peak position and $v_{0}$ is the Raman peak shift for an unstressed diamond monocrystal $\left(1332.5 \mathrm{~cm}^{-1}\right)$.

The Raman mapping method applied for $20 \times 20 \mu \mathrm{m}^{2}$ samples area and equation 1, allowed obtaining the maps of the residual stress distribution for each temperature. Examples of obtained 


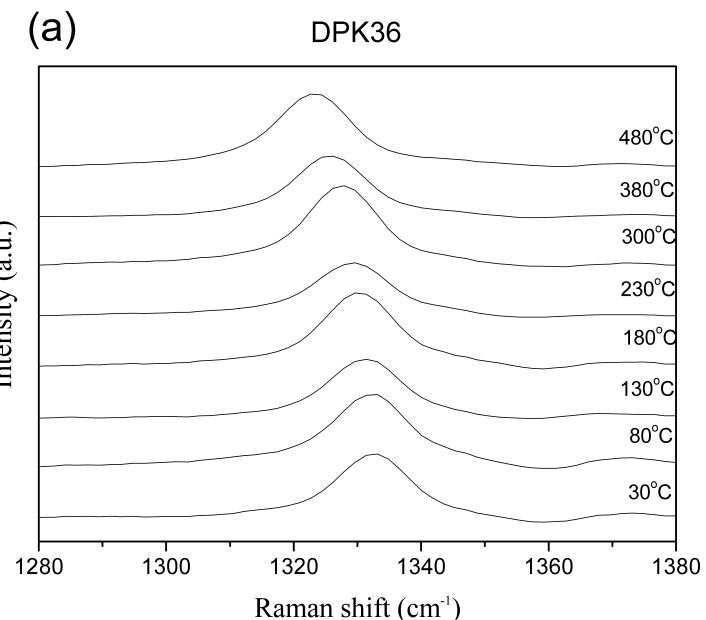

(b)

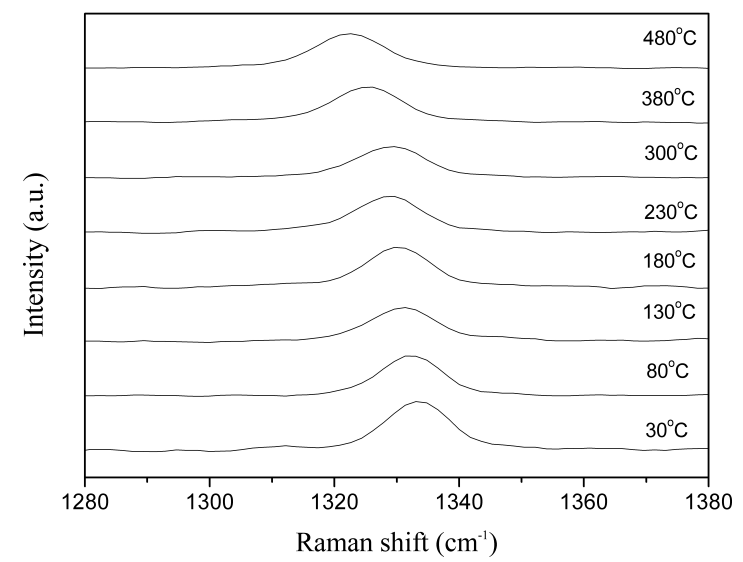

Fig. 1. Typical Raman spectra obtained for (a) DPK36 and (b) DPK37 at different temperatures.

Raman maps for a chosen temperature are presented in Fig. 2. At first sight it is obvious that the level of stress varies between the mapped regions; for DPK36 the stress is slightly comprehensive or even near zero and for DPK37 the level of stress is higher but also comprehensive in character. Moreover, at the top of the map (Fig. 2b) some kind of defect is observed which is a source of tensile intrinsic stress and, therefore, lowers the total stress level.

The frequency shift of the diamond Raman band towards lower wavenumbers at higher temperatures indicates a modification of the level and character of the residual stress. Table 2 shows the calculated stress values from Raman spectra. As can be seen, at $30{ }^{\circ} \mathrm{C}$, in both samples, the stress

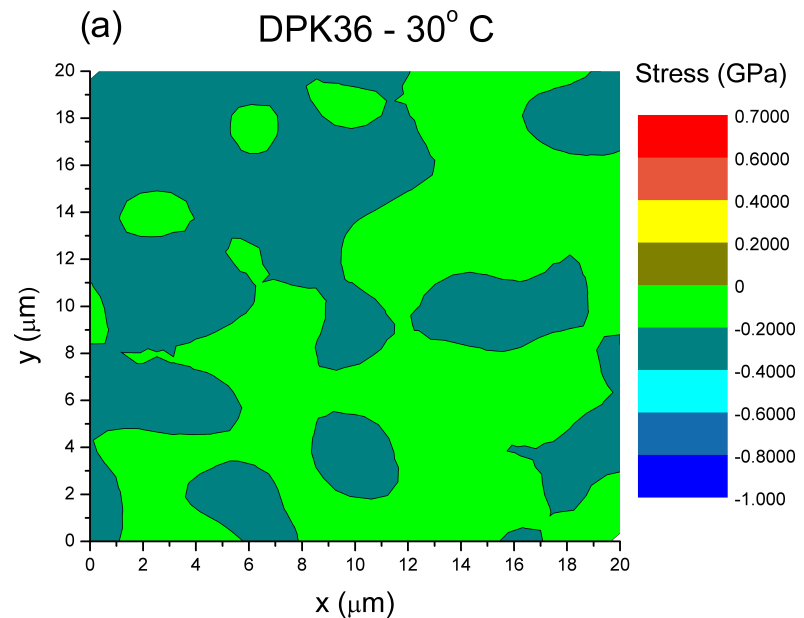

(b)

DPK37 $-30^{\circ} \mathrm{C}$

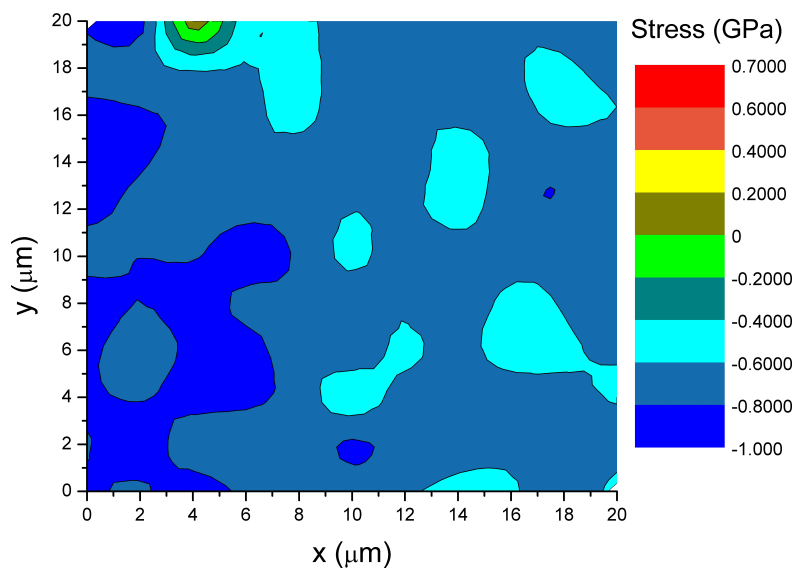

Fig. 2. Variations in residual stress on $20 \times 20 \mu \mathrm{m}^{2}$ area for (a) DPK36 and (b) DPK37 samples, obtained by the Raman mapping method using equation 1 at $30^{\circ} \mathrm{C}$.

was comprehensive in character and increased with increasing temperature. The stress for temperatures over $80{ }^{\circ} \mathrm{C}$ was converted into tensile stress, and at the highest temperature the residual stress for both samples achieved values above $5 \mathrm{GPa}$. In fact, Woehrl et al. [10] observed exactly the opposite trend for CVD diamond films (deposited on silicon $\left.\left(\begin{array}{lll}1 & 0 & 0\end{array}\right)\right)$ of thicknesses ranging from 7 to about $14 \mu \mathrm{m}$. They reported that at room temperature all samples had tensile residual stress which changed with increasing temperature to comprehensive one, independently of the deposition conditions. It should be noted that their results were obtained using substrate curvature method, but even so, it is unlikely that the two commonly used techniques would give such divergent results. 
It is important to mention that a shift of the diamond band appears not only on changing stress but also on increasing temperature due to an increase in vibration energy. The Klemens model [14] describes the behaviour of optical phonon in solid state as a function of temperature. The change in vibration energy is related to the change in the bond lengths as a result of increasing value of lattice constants. Residual stress changes with increasing temperature because CTE of diamond and silicon substrate is temperature dependent according to the following equation [15-17]:

$$
\alpha_{\text {film } / \text { substrate }}=c+\alpha T+\beta T^{2}+\gamma T^{3}+\delta T^{4}
$$

Parameters $c, \alpha, \beta, \gamma$ and $\delta$ are presented in Table 1.

Table 1. Parameters describing the temperature changes in the coefficient of thermal expansion for diamond and silicon substrate.

\begin{tabular}{ccc}
\hline & $\mathrm{Si}$ & Diamond \\
\hline \hline $\mathrm{c}$ & -2.15 & -1.36 \\
$\alpha$ & $2.47 \times 10^{-2}$ & $8.79 \times 10^{-3}$ \\
$\beta$ & $-3.82 \times 10^{-5}$ & $3.98 \times 10^{-7}$ \\
$\gamma$ & $2.67 \times 10^{-8}$ & $-6.18 \times 10^{-9}$ \\
$\delta$ & $-6.87 \times 10^{-12}$ & $+2.78 \times 10^{-12}$ \\
\hline
\end{tabular}

After deposition, no significant formation of new defects or incorporation of defects that include grain boundaries, dislocations, voids and impurities in the diamond film should occur. Increasing the temperature should raise mainly thermal stress in the layer.

In a recent publication Guillemet et al. [12] have evaluated thermal stress by two methods, one of which is usually applied in the finite element analysis (FEA) for the simulation of thermal stress [12, 18-20] using equation 3:

$\sigma_{T h}=\left(\frac{E_{d}}{1-v_{d}}\right) \cdot \int_{T_{0}}^{T_{\text {deposition }}}\left(\alpha_{f i l m}(T)-\alpha_{\text {substrate }}(T)\right) d T$,

where $E_{d}$ is the Young's modulus of diamond $\left(E_{d}=1150 \mathrm{GPa}\right), v_{d}$ is the Poisson's ratio of diamond $\left(\nu_{\mathrm{d}}=0.07\right), \alpha_{\text {film }}(\mathrm{T})$ and $\alpha_{\text {substrate }}(\mathrm{T})$ are the CTE temperature dependencies of the diamond film and the substrate material, respectively, and $\mathrm{T}_{\text {deposition }}$ and $\mathrm{T}_{0}$ are the deposition and room temperatures, or temperature of the sample, respectively.

The second method is based on the assumption that the diamond film and silicon substrate behave like a bi-metal bending plate. In this case, thermal stress will cause bending with some specific radius of curvature 1/R. Plate bending theory allows evaluation of a hypothetic value of this curvature, as reported in $[5,21]$. It is possible to calculate the mean bending stress in the diamond film which is equivalent to the stress according to equation 4:

$\sigma_{\text {Th-plate-bending }}=\frac{1}{R} \cdot \frac{Y_{d} \cdot d_{\text {film }}^{3}+Y_{s} \cdot d_{\text {substrate }}^{3}}{6 \cdot d_{\text {film }} \cdot\left(d_{\text {film }}+d_{\text {substrate }}\right)}$

where $Y_{d}=E_{d} /\left(1-v_{d}\right), Y s=E_{s} /\left(1-v_{s}\right), E_{s}$ is the Young's modulus of silicon $\left(E_{s}=170 \mathrm{GPa}\right), v_{d}$ is the Poisson's ratio of silicon $\left(v_{d}=0.42\right), d_{\text {film }}$ and $\mathrm{d}_{\text {substrate }}$ are the thicknesses of the diamond film and the silicon wafer, respectively $\left(\mathrm{d}_{\text {film }}=4.46 \mu \mathrm{m}\right.$ or $0.34 \mu \mathrm{m}, \mathrm{d}_{\text {substrate }}=0.4 \mathrm{~mm}$ ).

In order to calculate the evolution of thermal stress during re-heating of the samples, we propose a new approach. Since in equations 3 and 4 we took under consideration only different CTE values of the film and substrate (or in equation 4 fixed properties as for example the film thickness), we assume that the evolution of thermal stress in the film is reversible. It means that heating to some temperature after deposition causes changes equivalent to those caused by cooling after deposition, so $\mathrm{T}_{0}$ is a temperature equal to $30,80,130,180{ }^{\circ} \mathrm{C}$, respectively. This approach seems to be valid if the main source of thermal stress is the CTE mismatch between the film and the substrate.

The evaluated values of thermal stresses obtained from equations 3 and 4 are collected in Table 2 . The calculated values of stress components for different temperatures include the values of intrinsic stress obtained by subtracting the thermal stress from the residual stress according to the following equation 5 :

$$
\sigma_{\text {Inst }}=\sigma_{R e}-\sigma_{T h}
$$


Table 2. Residual, thermal, thermal from bi-metal theory stress, intrinsic values of stress, calculated by equations $1-5$, at different temperatures of heating.

\begin{tabular}{|c|c|c|c|c|c|c|c|}
\hline \multirow[t]{2}{*}{ Temperature } & \multicolumn{2}{|c|}{$\begin{array}{l}\text { Residual stress from } \\
\text { Raman shift } \sigma_{\operatorname{Re}} \\
\end{array}$} & \multirow[t]{2}{*}{$\begin{array}{l}\text { Thermal stress CTE in } \\
\text { temperature dependence } \sigma_{\mathrm{Th}}\end{array}$} & \multicolumn{2}{|c|}{$\begin{array}{l}\text { Thermal stress } \\
\text { bi-metal theory }\end{array}$} & \multicolumn{2}{|c|}{$\begin{array}{c}\text { Intrinsic stress } \\
\sigma_{\text {Inst }}=\sigma_{R e}-\sigma_{T h}\end{array}$} \\
\hline & $\overline{\text { DPK36 }}$ & DPK37 & & DPK36 & DPK37 & DPK36 & DPK37 \\
\hline${ }^{\circ} \mathrm{C}$ & & & GPa & & & & \\
\hline 30 & -0.198 & -0.695 & -0.481 & -0.270 & -0.368 & 0.282 & -0.214 \\
\hline 80 & 0.076 & -0.112 & -0.399 & -0.249 & -0.34 & 0.475 & 0.286 \\
\hline 130 & 0.478 & 0.557 & -0.320 & -0.216 & -0.295 & 0.798 & 0.877 \\
\hline 180 & 1.048 & 1.162 & -0.245 & -0.178 & -0.242 & 1.293 & 1.407 \\
\hline 230 & 1.696 & 1.895 & -0.178 & -0.138 & -0.187 & 1.874 & 2.073 \\
\hline 300 & 2.667 & 2.400 & -0.100 & -0.085 & -0.116 & 2.767 & 2.500 \\
\hline 380 & 3.564 & 3.855 & -0.034 & -0.036 & -0.049 & 3.598 & 3.889 \\
\hline 480 & 5.122 & 5.520 & 0.014 & 0.002 & 0.003 & 5.108 & 5.506 \\
\hline
\end{tabular}

Fig. 3 and Fig. 4 illustrate the results presented in Table 2. As shown, the thermal stress in both cases decreases with increasing temperature, which is in good agreement with expectations since the difference in CTE between the substrate and the film decreases. The interesting observation is that, on average, the intrinsic stress measured on the area of $20 \times 20 \mu \mathrm{m}^{2}$ for DPK36 sample is tensile in character, while for DPK37 it is comprehensive in character, although many of researchers reported that intrinsic stress is usually tensile in CVD diamond films [21] (film thickness $425 \mu \mathrm{m}$ ). The difference in character of stress between these two films is due to the fact that DPK36 film is over 10 times thicker than DPK37. Fan et al. [5] reported that for thicker film, the tensile residual stress (film thickness 1.7 to $48 \mu \mathrm{m}$ ) was observed, but all intrinsic stresses were tensile. Guillemet et al. [12] also observed tensile intrinsic stress but for thinner films; it was almost equal zero (film thickness 2.5 to $62 \mu \mathrm{m})$.

It is important to note that in the Raman spectra of DPK36 the peak around $1150 \mathrm{~cm}^{-1}$, which is assigned to transpolyacetylene in grain boundaries [21], was observed at all temperatures, whereas in the spectra of DPK37 it was not. The appearance of tensile or comprehensive intrinsic stress means that the diamond film is under-dense or over-dense, respectively. From this point of view, the strongly tensile trend of intrinsic stress at high temperature is understandable since after deposition there is no significant incorporation of new impurities into the layer. At the same time, with increasing temperature the total area of the sample increases, therefore, the total density of defects decreases.

A comparison between the results of thermal stress calculated from equations 3 and 4 is shown in Fig. 4. Thermal stress at $430{ }^{\circ} \mathrm{C}$ becomes nearly zero. In the first approach (equation 3), only the temperature dependencies of the film and substrate CTE have been taken under consideration, however, in the second approach (equation 2) besides CTE, also the thickness of the film and substrate impact on final thermal stress value was considered. As shown in Fig. 4, the largest differences between the values obtained for these two approaches are observed for the lowest temperatures. The maximum discrepancies are of about $0.2 \mathrm{GPa}$ and 0.11 GPa for DPK36 and DPK37, respectively. The results obtained by the two methods are in better agreement when the films are thinner and the temperature does not exceed $100{ }^{\circ} \mathrm{C}$, or when the films are thicker in the temperature range of $180^{\circ} \mathrm{C}$ to $300{ }^{\circ} \mathrm{C}$.

\section{Conclusions}

In this paper we have shown that on heating of the diamond samples, residual stress and 
(a)

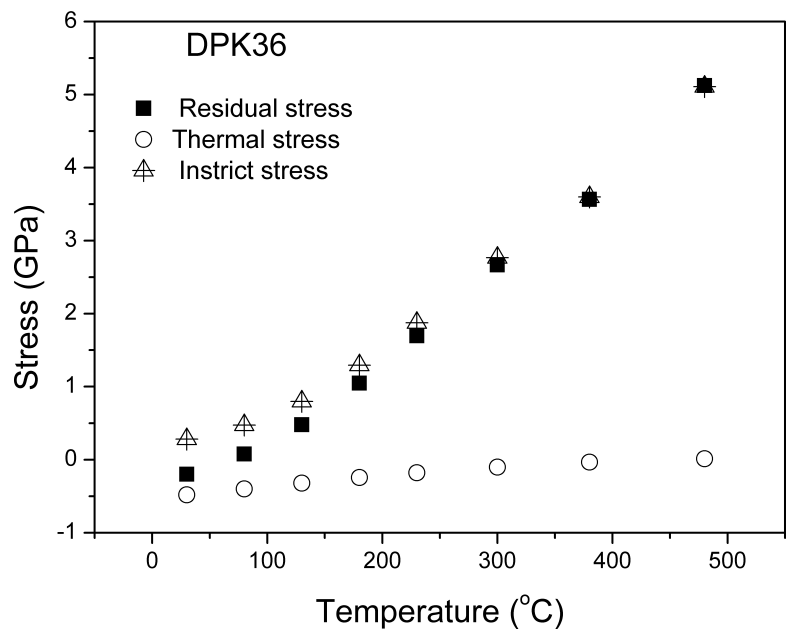

(b)

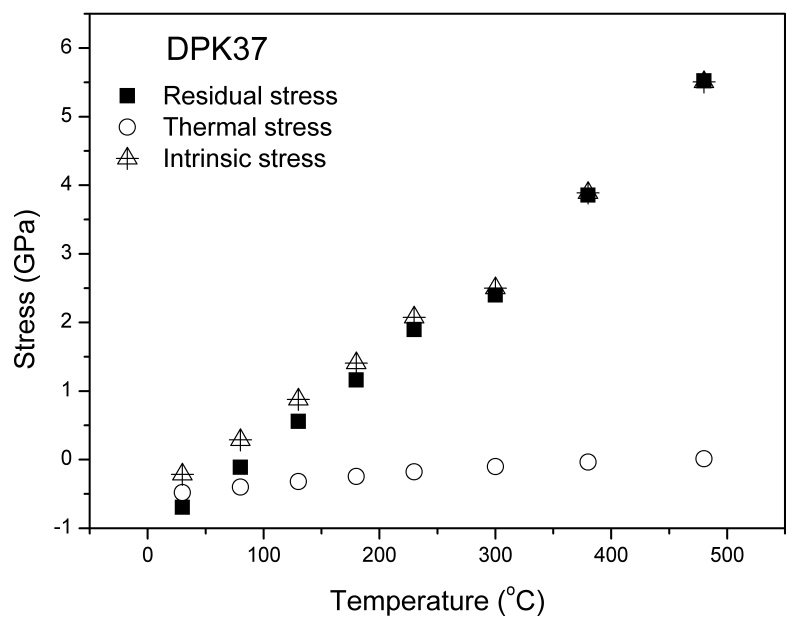

Fig. 3. Temperature dependence of stress for (a) DPK36 and (b) DPK37 samples.

its components change in different ways. The residual stress changed its character from comprehensive to tensile; its final value at $480{ }^{\circ} \mathrm{C}$ was above $5 \mathrm{GPa}$. At the same time the thermal stress calculated by the two methods remained comprehensive with increasing temperature and decreased almost to zero. The results obtained for thin diamond films by the two methods used for the evaluation of thermal stress are in quite a good agreement. We showed new relationships associated with stress. The study shows that temperature has the main impact on the residual stress. This is evidenced by the Raman shift changes, which are not only attributed to the residual stress but also

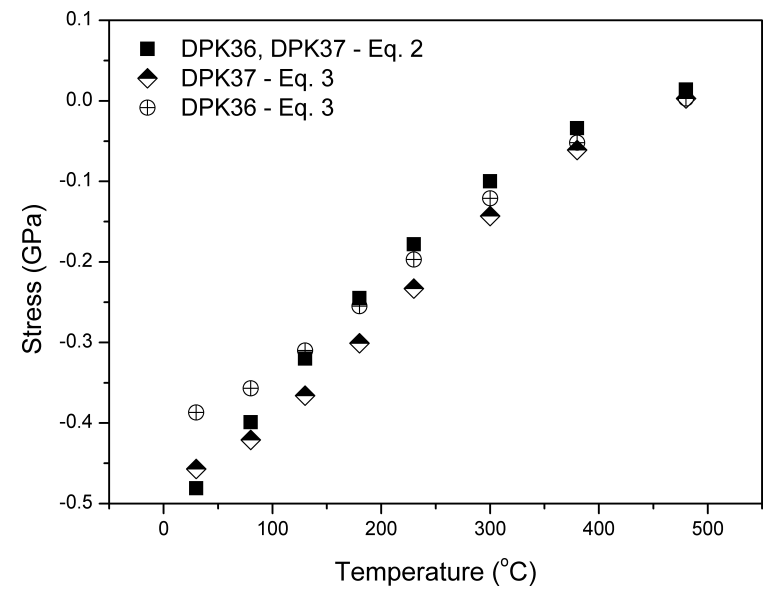

Fig. 4. Comparison of thermal stress in the temperature range from $30{ }^{\circ} \mathrm{C}$ to $480{ }^{\circ} \mathrm{C}$ calculated by different models.

to evolution of energy vibration of the first order phonon of diamond, as described by the Klemens model [14]. A better description of all types of stresses in thin diamond layers needs more studies which will be carried out in the future.

\section{Acknowledgements}

This work was supported in part by the Research Project of Poznan University of Technology 06/62/DSPB/0415/2015.

\section{References}

[1] Sato H., KASU M., Diam. Relat. Mater., 24 (2012), 99.

[2] Denisenko A., Kohn E., Diam. Relat. Mater., 14 (2005), 491.

[3] Torz-Piotrowska R., FABisiak K., PAProcki K., SzYBOWICZ M., STARYGA E., BANASZAK A., $J$. Phys. Chem. Solids, 72 (2011), 1225.

[4] Mosińska L., Fabisiak K., Papocki K., KowalSKA M., Popielarski P., Szybowicz M., Electrochim. Acta, 104 (2013), 481.

[5] Fan Q.H., Gracio J., Pereira E., Diam. Relat. Mater., 9 (2000), 1739.

[6] Windischmann H., Gray K.J., Diam. Relat. Mater., 4 (1995), 837.

[7] Fabisiak K., Torz-Piotrowska R., Staryga E., SzYBOWICZ M., PAProcki K., BANASZAK A., Popielarski P., Mater. Sci. Eng. B-Adv., 177 (2012), 1352.

[8] Kght D.S., White W.B., J. Mater. Res., 4 (2) (1989), 385.

[9] Ager J.W., Drory M.D., Phys. Rev. B, 48 (1993), 2601.

[10] Woehrl, N., Hirte T., Posth O., Buck V., Diam. Relat. Mater., 18 (2009), 224. 
[11] Liscia di E.J., Álvarez F., Burgos E., Halac E.B., Reinoso M., Mater. Sci. Appl., 4 (2013), 191.

[12] Guillement T., Xie Z.Q., Zhou Y.S., PARK J.B., Veillere A., Xiong W., Heintz J.M., Silvain J.F., Chandra N., LU Y.F., ACS Appl. Mater. Inter, 3 (2011), 4120.

[13] Ralchenko V.G., Smolin A.A., PereverzeV V.G., Obraztsova E.D., Korotoushenko K.G., Diam. Relat. Mater., 4 (1995), 754.

[14] Klemens P.G., Phys. Rev., 148 (1996), 845.

[15] JEONG J.H., LEE S.Y., LEE W.S., BAIK Y.J., KWON D., Diam. Relat. Mater., 11 (2002), 1597.

[16] BRAndes E.A., Smithells Metals Reference Book, $6^{\text {th }}$ Edition, London, 1983.
[17] Slack G.A., Bartman S.F., J. Appl. Phys., 46 (1975) 89.

[18] Xu F., Zuo D., Lu W., Wang M., Zhang H., Key Eng. Mat., 375 - 376 (2008), 123.

[19] LiU C., TAng D., Adv. Mat. Res., 139 - 141 (2010), 456.

[20] LiU Z., Chen L., Liy C., Hei L., Song J., Chen G., TANG W., LV F., J. Mater. Sci. Technol., 26 (11) (2010), 991.

[21] Woehrl N., Buck V., Diam. Relat. Mater., 16 (4 - 7) (2007), 748.

Received 2015-01-12

Accepted 2015-03-28 